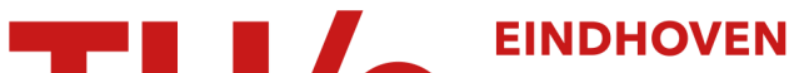 \\ UNIVERSITY OF \\ TECHNOLOGY
}

\section{Plasma rotation and momentum transport studies at JET}

\section{Citation for published version (APA):}

de Vries, P. C., Rantamäki, K. M., Asp, E., Corrigan, G., Eriksson, A., Giroud, C., Jenkins, I., Knoops, H. C. M., Mantica, P., Nordman, H., Strand, P., Tala, T., Weiland, J., \& Zastrow, K-D. (2005). Plasma rotation and momentum transport studies at JET. (European Fusion Development Agreement; Vol. JET-CP(06)03-05). EFDA.

Document status and date:

Published: 01/01/2005

\section{Document Version:}

Publisher's PDF, also known as Version of Record (includes final page, issue and volume numbers)

\section{Please check the document version of this publication:}

- A submitted manuscript is the version of the article upon submission and before peer-review. There can be important differences between the submitted version and the official published version of record. People interested in the research are advised to contact the author for the final version of the publication, or visit the $\mathrm{DOI}$ to the publisher's website.

- The final author version and the galley proof are versions of the publication after peer review.

- The final published version features the final layout of the paper including the volume, issue and page numbers.

Link to publication

\section{General rights}

Copyright and moral rights for the publications made accessible in the public portal are retained by the authors and/or other copyright owners and it is a condition of accessing publications that users recognise and abide by the legal requirements associated with these rights.

- Users may download and print one copy of any publication from the public portal for the purpose of private study or research.

- You may not further distribute the material or use it for any profit-making activity or commercial gain

- You may freely distribute the URL identifying the publication in the public portal.

If the publication is distributed under the terms of Article 25fa of the Dutch Copyright Act, indicated by the "Taverne" license above, please follow below link for the End User Agreement:

www.tue.nl/taverne

Take down policy

If you believe that this document breaches copyright please contact us at:

openaccess@tue.nl

providing details and we will investigate your claim. 
EFDA-JET-CP(06)03-05

P.C. de Vries, K.M. Rantamäki, E. Asp, G. Corrigan, A. Eriksson, C. Giroud, H.C.M. Knoops, P. Mantica, H. Nordman, P. Strand, T. Tala, J. Weiland, K.-D Zastrow and JET EFDA Contributors

\section{Plasma Rotation and Momentum Transport Studies at JET}


"This document is intended for publication in the open literature. It is made available on the understanding that it may not be further circulated and extracts or references may not be published prior to publication of the original when applicable, or without the consent of the Publications Officer, EFDA, Culham Science Centre, Abingdon, Oxon, OX14 3DB, UK."

"Enquiries about Copyright and reproduction should be addressed to the Publications Officer, EFDA, Culham Science Centre, Abingdon, Oxon, OX14 3DB, UK." 


\title{
Plasma Rotation and Momentum Transport Studies at JET
}

\author{
P.C. de Vries ${ }^{1}$, K.M. Rantamäki ${ }^{2}$, E. Asp ${ }^{3}$, G. Corrigan $^{1}$, A. Eriksson ${ }^{3}$, C. Giroud ${ }^{1}$,

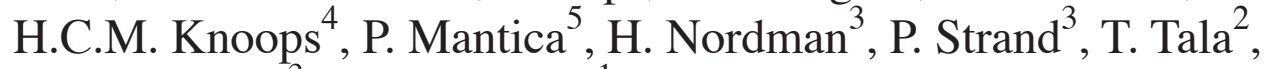 \\ J. Weiland ${ }^{3}$, K.-D Zastrow ${ }^{1}$ and JET EFDA Contributors*
}

${ }^{1}$ EURATOM/UKAEA Fusion Association, Culham Science Centre, Abingdon, OX14 3DB, UK

${ }^{2}$ VTT Technical Research Centre of Finland, EURATOM-Tekes, Espoo, Finland

${ }^{3}$ Chalmers University of Technology, EURATOM/VR Association, Göteborg, Sweden

${ }^{4}$ Eindhoven University of Technology, Dept. Applied Physics, Eindhoven, The Netherlands

${ }^{5}$ Istituto di fisica del plasma, Associazione Euratom-ENEA-CNR, Milan, Italy

* See annex of J. Pamela et al, "Overview of JET Results",

(Proc. 20 IAEA Fusion Energy Conference, Vilamoura, Portugal (2004).

Preprint of Paper to be submitted for publication in Proceedings of the

33rd EPS Conference,

(Rome, Italy 19-23 June 2006) 



\section{ABSTRACT.}

In many devices a relationship between viscosity and ion heat transport has been observed. This coupling can be attributed to turbulence, which is also a common feature in fluid dynamics. For plasmas, ITG turbulence theory predicts a one-to-one relationship, which is furthermore assumed in many plasma models. In this work, a detailed study on momentum and heat transport has been carried out. The research focussed on the determination of the Prandtl number, $\mathrm{P}_{\mathrm{r}} \equiv \chi_{\phi} / \chi_{\mathrm{i}}$, which describes the coupling between momentum and heat transport. A better understanding of plasma rotation and momentum transport is of importance for the development of low torque ITER scenarios.

An experimental study on plasma rotation has been carried out on predominantly Neutral Beam (NBI) heated JET discharges. The JET neutral beams are injected at 2 different octants, each injecting 8 independent neutral beams. Each beam has a tangential component and thus applies a torque to the plasma. For standard operations, NBI is in co-current direction.

Charge Exchange Recombination Spectroscopy (CXRS) [2] is used to measure the toroidal rotation velocity and ion temperature profiles. The JET CXRS diagnostic determines the profiles at 9 radial locations. The measured quantities are those of Carbon ions. In this study, it is assumed that the deuterium ions have the same temperature and velocities as the carbon ions. Especially for plasmas with large pressure gradients, such as those with an Internal Transport Barrier (ITB), this assumption does not necessarily hold and the rotation profiles need to be corrected [3].

In many devices a relationship between viscosity and ion heat transport has been observed. This coupling can be attributed to turbulence, which is also a common feature in fluid dynamics. For plasmas, ITG turbulence theory predicts a one-to-one relationship [1], which is furthermore assumed in many plasma models. In this work, a detailed study on momentum and heat transport has been carried out. The research focussed on the determination of the Prandtl number, $\operatorname{Pr} \int \mathrm{cf} / \mathrm{ci}$, which describes the coupling between momentum and heat transport. A better understanding of plasma rotation and momentum transport is of importance for the development of low torque ITER scenarios. An experimental study on plasma rotation has been carried out on predominantly neutral beam (NBI) heated JET discharges. The JET neutral beams are injected at 2 different octants, each injecting 8 independent neutral beams. Each beam has a tangential component and thus applies a torque to the plasma. For standard operations, NBI is in co-current direction.

Charge exchange recombination spectroscopy (CXRS) [2] is used to measure the toroidal rotation velocity and ion temperature profiles. The JET CXRS diagnostic determines the profiles at 9 radial locations. The measured quantities are those of Carbon ions. In this study, it is assumed that the deuterium ions have the same temperature and velocities as the carbon ions. Especially for plasmas with large pressure gradients, such as those with an internal transport barrier (ITB), this assumption does not necessarily hold and the rotation profiles need to be corrected [3].

\section{ION TEMPERATURE AND ROTATION PROFILES}

Firstly the relationship between the ion temperature and angular rotation profile has been studied. 
A statistical analysis on the ratio of the angular rotation frequency to the ion temperature, $\omega / \mathrm{T}$, showed a clear difference between the ITB and the H-mode discharges. The statistics was done for all discharges with CXRS measurements over the period 2000-2004 with $\mathrm{P}_{\mathrm{NBI}}>6 \mathrm{MW}$. For the ITB discharges, shown in figure 1 (left) the ratio is very similar at all the 7 radial measuring points, i.e. there is a small statistical spread. This means that the two radial profiles are very similar. On the contrary, for the H-mode discharges, shown in figure 1 (right) the difference between the channels is much larger. This shows that the angular rotation profile and the temperature profile do not match each other in the H-mode.

The profiles can also be characterised by their gradient lengths as shown in figure 2 (left), where the inverse temperature gradient length is plotted versus that of the rotation velocity for a large series of ELMy H-mode discharges. As can be seen, in the central region (red) the inverse temperature gradient length is clearly larger than the rotation one. In the outer region (green) the gradient lengths are closer to each other.

\section{MACH NUMBER OF JET PLASMAS}

The Mach number was calculated for various operation scenarios. The dimensionless Mach number can be used to compare plasma rotation in various de-vices or different plasma scenarios. The Mach number is defined as the ratio of the kinetic to the thermal speed of the plasma species, $\mathrm{M}=(\mathrm{m} / \mathrm{e})^{1 / 2} \mathrm{v} / \mathrm{T}^{1 / 2}$, where $\mathrm{m}$ is the mass, $\mathrm{v}$ is the toroidal velocity in $[\mathrm{m} / \mathrm{s}]$ and the temperature, $\mathrm{T}$, is given in eV. For NBI heated JET discharges a difference in the average Mach number between L-mode, Type III and Type I ELMy H-modes was found. Figure 2 shows the central Mach number for 3 scenarios: type I ELMy H-mode (blue), type III ELMy H-mode (red) and ITB-discharges (green) as a function of the NBI power fraction. L-mode discharges are not shown in the figure, but they have a significantly lower Mach number than the others. The ITB discharges have clearly larger Mach numbers than either of the H-modes, which is explained by the differences in the temperatures. The $\mathrm{H}$-mode plasmas have on the average $\mathrm{M}=0.4$. The Mach number decreases, as expected, for discharges with a lower fraction of NBI power, e.g. NBI torque.

\section{MOMENTUM AND ION HEAT DIFFUSIVITY}

The change in the Mach number does not necessarily mean a change in the Prandtl number, even though the ratio of torque to input power remained constant. To study the Prandtl number, several type I ELMy H-mode discharges have been analysed in detail. These discharges were chosen to have equal electron and ion temperatures, $\mathrm{T}_{\mathrm{e}} \approx \mathrm{T}_{\mathrm{i}}$ and the flat density profiles, i.e. $\mathrm{R} / \mathrm{L}_{\mathrm{n}}<2$. Here, the inverse density gradient length $1 / \mathrm{L}_{\mathrm{n}}$ is defined as the derivative (with respect to the $\sqrt{ } \psi$ coordinates) of the natural logarithm. These pulses were also analysed using the JETTO [4] transport code. A characteristic of high density H-mode plasmas in JET is that the NBI transfer energy to the ions in the centre, while the momentum is deposited off-axis.

This set of discharges differed in the ion temperature gradient length from low gradient lengths 
$<\mathrm{R} / \mathrm{L}_{\mathrm{T}}>\approx 3$ to those that where close to the ITG threshold $<\mathrm{R} / \mathrm{L}_{\mathrm{T}}>\approx 5$. The Prandtl number was in the range of $0.18<\mathrm{P}_{\mathrm{r}}<0.35$, which is clearly below unity, as can be seen in Figure 3 (left). Those discharges with an ion temperature gradient length close to the ITG threshold showed the smallest Prandtl numbers. This is different to the ITG theory, which predicts $\chi_{\phi} \sim \chi_{i}$. Moreover, predictive modelling using the Weiland model [5], assuming that the momentum diffusivity was a constant fraction of the ion heat diffusivity, found the obtained rotation to agree with the experimental ones for Prandtl numbers of $\mathrm{P}_{\mathrm{r}}=0.2$ to 0.3 .

Even though the local diffusion coefficients clearly deviate from each other, the global parameters, the confinement times for momentum and ion energy do agree. Figure 3 (right) shows that the momentum confinement time is close to the ion energy replacement time (blue), defined as the ratio of the total ion energy to the power transferred to the ions. The total energy confinement time (black) is often larger than the momentum confinement time.

\section{SUMMARY}

The rotation and momentum transport has been studied at JET. The analysis showed that the rotation and temperature profiles match each other for the ITB discharges but not for the H-mode plasmas. This could be explained by the difference in NBI energy and momentum deposition in high density $\mathrm{H}$-mode plasmas. The central Mach numbers differ between the ELMy H-modes and the ITB discharges. Higher values were found for the ITB discharges. The effective diffusion coefficients for ion heat and momentum deviate in the gradient region of JET plasmas, giving a Prandtl number of $\mathrm{P}_{\mathrm{r}}=0.2$ to 0.3 .

\section{ACKNOWLEDGEMENTS}

This work was made possible with financial support of the EPSRC, EURATOM, FOM and carried out under the European Fusion Development Agreement.

\section{SUMMARY}

[1]. N. Mattor and P.H. Diamond, Phys. Fluids 31 (1988) 1180.

[2]. H. Weisen, et al., Nucl. Fusion 29 (1989) 2187.

[3]. D. Testa, et al, Phys. Plasmas 9 (2002) 243.

[4]. G. Genacchi and A. Taroni, ENEA Report No. ENEA RT/TIB 1988(5), 1988.

[5]. J. Weiland, Collective Modes in Inhomogeneous Plasma, IOP Publishing, Bristol 2000. 


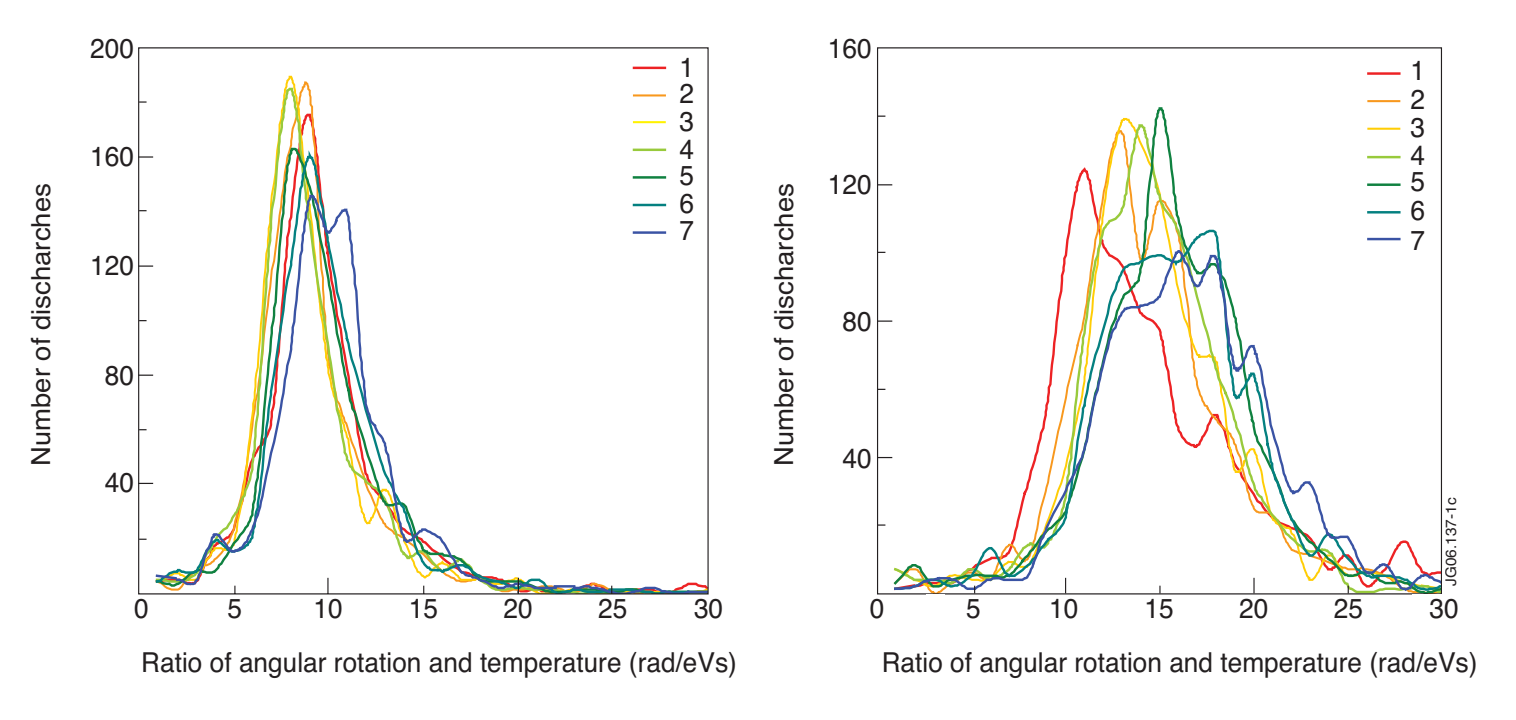

Figure 1: Statistical analysis of the ratio between the angular rotation frequency and the ion temperature, w/T, for ITB discharges on the left and for H-mode discharges on the right.

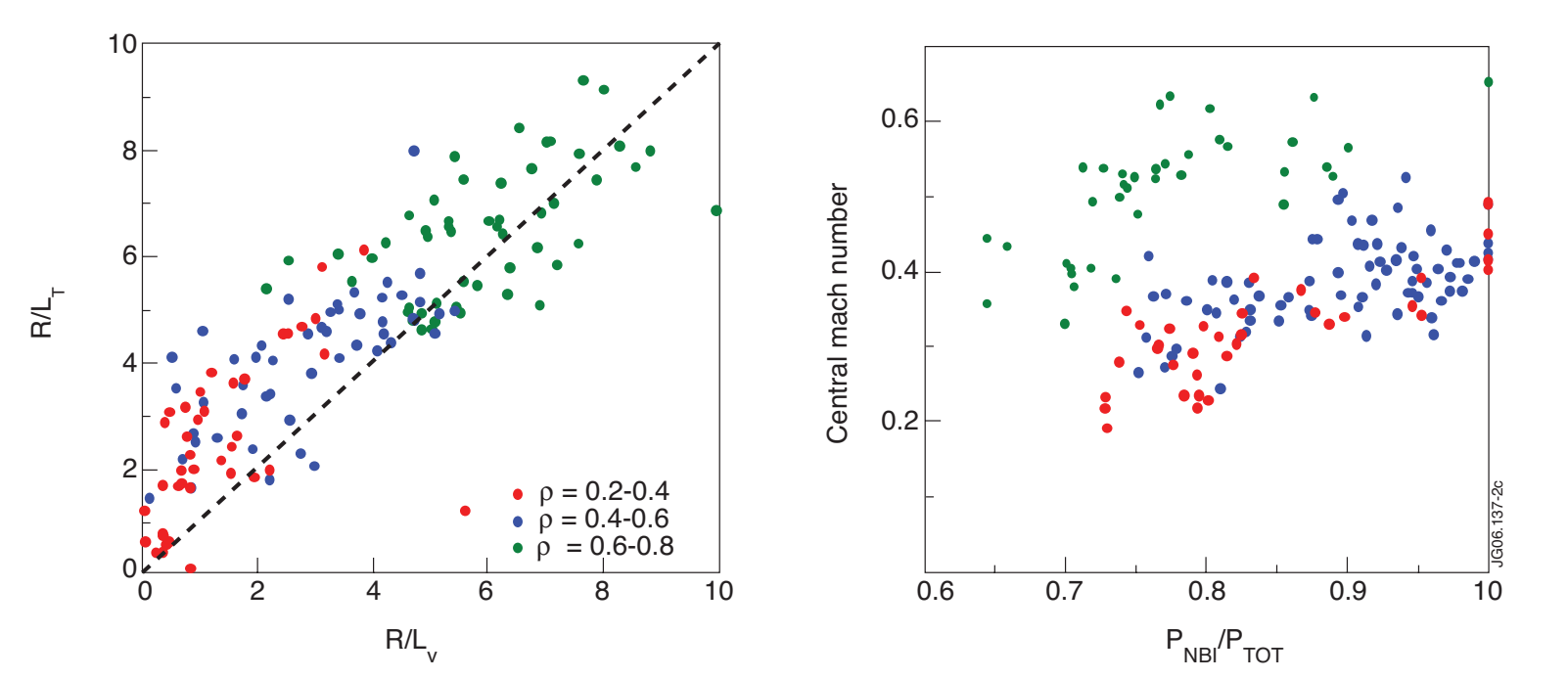

Figure 2: The inverse gradient lengths of the temperature profile versus that of rotation profile calculated in 3 plasma regions for H-mode only (left). The central Mach number versus the fraction of NBI power (right).

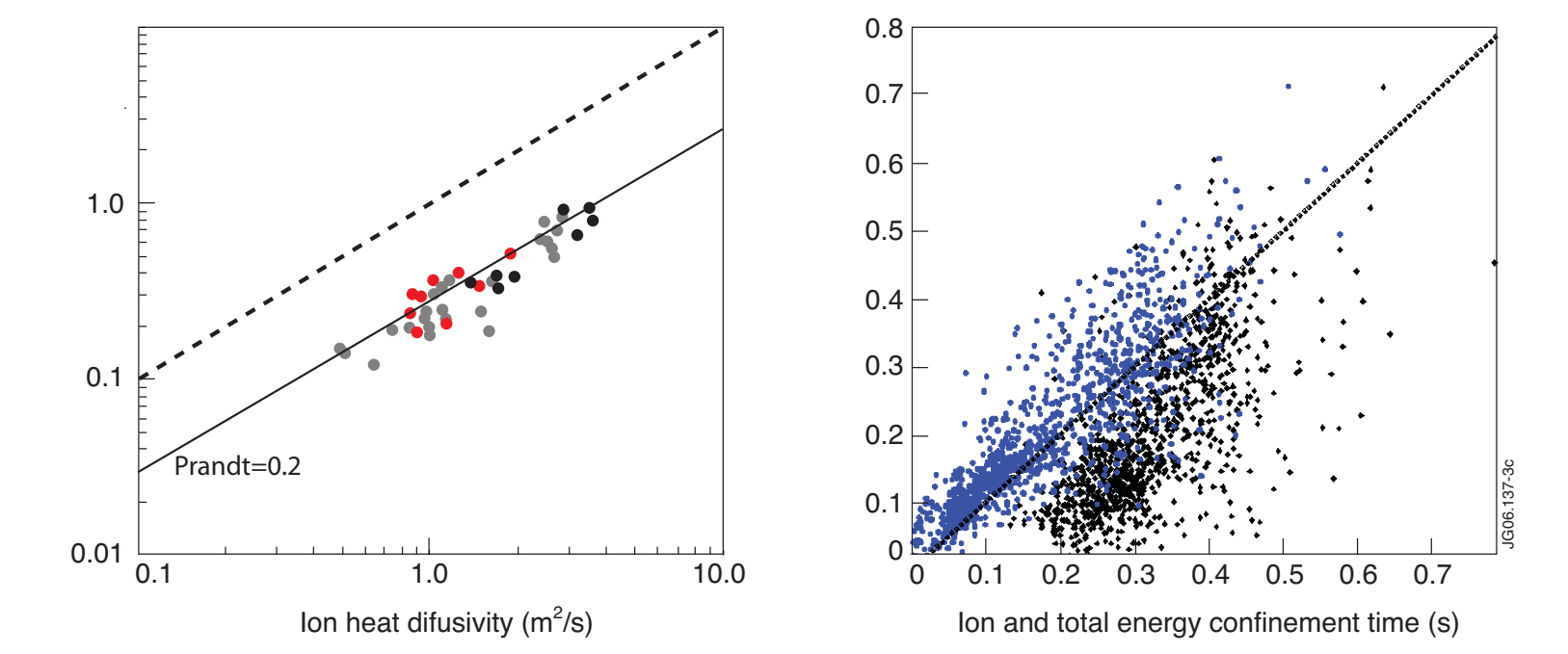

Figure 3: (Left) The momentum diffusivity as a function of the ion heat diffusivity averaged over the gradient region $0.3<r<0.7$ (left) for various discharges. (Right) The momentum confinement time versus the ion energy replacement time (blue) and the total energy confinement time (black). 